\title{
LOS 15 AÑOS DEL FOCEM
}

\author{
Luciano Wexell Severo' \\ Mônica Karla Magalhães Lima²
}

\begin{abstract}
El objetivo del presente trabajo es analizar los primeros quince años (2006-2020) del Fondo para la Convergencia Estructural del Mercosur (Focem) como mecanismo de disminución de las asimetrías entre las economías del bloque. El artículo está dividido en tres partes además de la introducción. Primero se presentan los avances del proceso de institucionalización de la integración sudamericana durante los años 2000, afianzada en la necesidad de deconstruir asimetrías. A continuación, se abordará el Focem y sus 53 proyectos aprobados. Para finalizar, se interpretan las nuevas posibilidades post-2015, en un escenario de retracción de las iniciativas integracionistas y, recientemente, de transferencia de la administración fiduciaria de los recursos del Focem para el Fondo Financiero para el Desarrollo de los Países de la Cuenca del Plata (Fonplata).
\end{abstract}

Palabras clave: América Latina; integración; financiamiento; Focem.

\section{OS 15 ANOS DO FOCEM}

0 objetivo deste artigo é analisar os primeiros quinze anos (2006-2020) do Fundo para a Convergência Estrutural do Mercosul (Focem) como mecanismo de redução das assimetrias entre as economias do bloco. 0 texto está dividido em três partes, além da introdução. Em primeiro lugar, é apresentado o processo de institucionalização da integração sul-americana ao longo dos anos 2000 , sustentado na desconstrução de assimetrias. Em seguida, será abordado o Focem e seus 53 projetos aprovados. Por fim, interpretam-se as novas possibilidades pós-2015, em um cenário de retração das iniciativas de integração e, recentemente, de transferência da administração fiduciária de recursos do Focem para o Fundo Financeiro para o Desenvolvimento dos Países da Bacia do Prata (Fonplata).

Palavras-chave: América Latina; integração; financiamento; Focem.

\section{THE 15 YEARS OF FOCEM}

The purpose of this article is to analyze the first fifteen years (2006-2020) of the Mercosur Structural Convergence Fund (FOCEM) as a mechanism to reduce the asymmetries within the bloc's economies. We divide the article into three sections in addition to the introduction. In the first section, we discuss the institutionalization process of South American integration throughout the 2000s based on the deconstruction of asymmetries. Then, in the second section, we assess the Focem and its 53 approved projects. Finally, in the third section, we analyze what are the new possibilities post-2015 in a context of retraction of integration initiatives retraction and, recently, of transferring the fiduciary management of financial resources from FOCEM to Financial Fund for the Development of the Countries of the River Plate Basin (FONPLATA).

Keywords: Latin America; integration; financing; FOCEM.

JEL: F36.

DOI: http://dx.doi.org/10.38116/rtm23art10

1. Docente de la Universidad Federal de Integración Latinoamericana (Unila); y coordinador del Observatorio de Integración Económica de América del Sur (Obiesur). Correo electrónico: <luciano.severo@unila.edu.br>. Orcid: <https://orcid.org/0000-0002-1484-7398>.

2. Internacionalista egresada de Unila en 2018. Correo electrónico: <monicakarla08@gmail.com>. Orcid: <https:// orcid.org/0000-0003-4387-6689>. 
Data de envio do artigo: 30/4/2020; Data de aceite: 17/9/2020.

\section{INTRODUCCIÓN}

Es de extrema importancia realizar un balance de los quince años del Fondo para la Convergencia Estructural del Mercosur ${ }^{3}$ (Focem), un instrumento que pese a sus limitaciones fue efectivo en el combate a las asimetrías entre las economías del bloque. Su experiencia ha generado muchas expectativas y necesita ser evaluada. El Focem ha provisto de recursos y promocionado la contribución de los gobiernos locales para proyectos muy relevantes, sobre todo en Paraguay y Uruguay, países que recibieron más del $94 \%$ de los montos.

Es posible identificar que el Focem ha tenido tres periodos distintos: el primero, entre 2006 y 2010, fase de adaptación técnico-burocrática y de acumulo de recursos; el segundo, entre 2011 y 2015, de fuerte inyección de financiamientos, especialmente en la infraestructura física de Paraguay y Uruguay; y el tercero, post-2015, marcado por la suspensión de los aportes financieros por parte de los países y del congelamiento de las iniciativas de integración regional. Recientemente, a fines de 2019, el Focem ingresó en otra etapa, en un nuevo formato institucional ahora vinculado al Fondo Financiero para el Desarrollo de los Países de la Cuenca del Plata (Fonplata), que asumió la administración fiduciaria de los recursos financieros del fondo del Mercosur.

Como parte de la metodología de esta investigación se realizó una revisión bibliográfica de los principales trabajos publicados sobre el mecanismo. En esa búsqueda, fueron usados libros, artículos científicos, documentos oficiales e informes institucionales. A pesar de la insuficiencia de información y en algunos casos la ausencia de datos, fueron elaboradas series estadísticas, tablas y gráficas sobre el desempeño del Focem entre 2006 y 2020. Por fin, se aprovecharon algunos fragmentos de entrevistas concedidas por técnicos del Mercosur en la ciudad de Montevideo, en octubre de 2017.

En su nueva etapa, las limitaciones y los obstáculos podrán ser superados y ese importante mecanismo, potencializado. En la retomada post-Covid, los países del Mercosur precisarán de ágiles instrumentos de financiamiento a la infraestructura, de fomento al desarrollo y de cohesión social. Ese necesario rol podría ser desempeñado por el Focem.

\section{ANTECEDENTES}

Una singular concomitancia de factores (mundiales, regionales y nacionales) contribuyó para reforzar las históricas proposiciones de estrechar los vínculos entre 
las naciones de América del Sur al inicio de los años 2000. Entre los principales acontecimientos se destacan el avance de la multipolaridad en el Sistema Internacional, que evidenció la pérdida relativa de poder por parte de Estados Unidos tras una década de hegemonía prácticamente incontestable; la asunción al poder, en diversas naciones de la región, de agrupaciones políticas reivindicadoras de una mayor presencia del Estado; la preponderancia del entendimiento por parte de Itamaraty y otros importantes entes del gobierno brasileño sobre la importancia de la región para el desarrollo y la inserción internacional de Brasil y el rol que Brasil pueda tener para impulsar el desarrollo y mejorar la inserción internacional de la región; y el fuerte aumento de los precios internacionales de las materias primas e insumos básicos exportados por las economías sudamericanas entre 2003 y 2014. La fusión de todos esos componentes, además de otros con menor relevancia, posibilitó que América del Sur entrara al siglo XXI tejiendo audaces confabulaciones sobre la integración regional.

A lo largo de los años 1990, como resultado de las renegociaciones de la elevada deuda externa contraída durante los años 1970 y sufrida en los años 1980, las economías latinoamericanas adoptaran políticas de apertura comercial y financiera. Después de pasada la llamada década perdida nuevamente se logró atraer voluminosas sumas de recursos para la región: los capitales buscaron la elevada remuneración de los papeles de deuda y disfrutaron de un desordenado proceso de privatización y desnacionalización de activos. En contrapartida, el pago de intereses y el envío de remesas de lucros para el exterior también crecieron, como consecuencia de la financiarización y de la presencia dominante de capitales transnacionales en sectores estratégicos de las economías de América del Sur (Severo, 2019, p. 360). Dicho de otra manera, la creciente apertura comercial y de la cuenta de capital de los países periféricos amplió sus dificultades estructurales vinculadas a la ausencia de recursos para el financiamiento del desarrollo.

Se observó un aumento sin precedentes de la vulnerabilidad externa y de los riesgos macroeconómicos en esas economías, lo que fue explicitado por las crisis ocurridas a finales de la década de 1990. Padula (2010, p. 134, traducción nuestra) asocia las turbulencias financieras en las economías emergentes con la "creciente volatilidad de flujos de capitales de corto plazo (especulativos), no relacionados al sector productivo". Los casos más representativos son los Tigres Asiáticos en 1997 y Rusia en 1998. En América Latina, los déficits en la balanza de pagos y las crisis tuvieron impacto en casi todos los países, en especial en Argentina, Bolivia, Brasil, Colombia, Ecuador, México, Paraguay, Uruguay y Venezuela (Cano, 2000, p. 49). Los colapsos financieros de Brasil en enero de 1999 y de Argentina en diciembre de 2001 sacudieron el llamado "Mercosur fenicio" (Caetano, 2006, p. 3). El bloque vivió su momento más delicado exactamente entre la megadevaluación 
brasileña y el fin del currency board argentino. Aún así, mantuvo la constancia del funcionamiento de sus actividades y reuniones presidenciales.

Bajo este escenario, en septiembre de 2000, después de más de 180 años de las independencias políticas que engendraron la mayoría de las repúblicas sudamericanas, los mandatarios de las doce naciones que constituyen la región se reunieron por primera vez en la historia sin la presencia de terceros países. Se realizó la I Reunión de los Presidentes de América del Sur, encuentro inusual que tuvo la capacidad de juntar a líderes políticos con distintas trayectorias y perspectivas para aglutinar esfuerzos de construcción conjunta. ${ }^{4}$ A partir de entonces las reuniones entre mandatarios se intensificaron. En julio de 2002 ocurrió la II Reunión de los Presidentes de América del Sur, en Guayaquil, Ecuador, ocasión en la cual se reafirmó la decisión de conformar un "espacio común sudamericano". El documento final hace referencia a la Iniciativa para la Integración de la Infraestructura Regional de Sudamericana (IIRSA).

Las crisis financieras de finales del siglo XX e inicios del nuevo milenio resultaron en la disminución de los márgenes para la adopción de medidas económicas de liberalización $\mathrm{y}$, al mismo tiempo, estimularon importantes cambios políticos en Argentina, Brasil y Uruguay. Desde el inicio de 2003, los nuevos gobiernos de las dos mayores naciones sudamericanas demostraron su apuesta en el fortalecimiento del Mercosur, con el manifiesto posicionamiento de que sería un error mantener el bloque centrado en una perspectiva únicamente comercial. Se trataba de construir un proceso más amplio. ${ }^{5}$ En la perspectiva de Garcia (2010, p. 161, traducción nuestra),

Brasil entendió que sólo a través del comercio no se pueden resolver los problemas de la construcción de una América del Sur integrada, justa y democrática. Por el contrario, la integración comercial puede, en las circunstancias actuales, agravar las asimetrías entre países más desarrollados con economías más complejas y diversificadas, como Brasil y Argentina, por un lado, y los otros, por otro. ${ }^{6}$

\footnotetext{
4. En el ámbito comercial se reafirmó el "compromiso con la construcción progresiva de un área de libre comercio en las Américas, cuyas negociaciones deberán estar terminadas a más tardar en el 2005". En el área de infraestructura, hubo grandes avances en la integración física, de energía, transportes y comunicaciones. Disponible en: <https://www. oei.es/historico/oeivirt/cumbre1.htm>.

5. Según Peña (2009, p. 57), la expansión del Mercosur tuvo dos perspectivas: una geográfica y otra de áreas de acción. "El primero se refiere al espacio de preferencias comerciales. A través de acciones de alcance parcial, se ha extendido una red de preferencias a otros países miembros de Aladi [Asociación Latinoamérica de Integración] y, en particular, a aquellos que han adquirido la condición de miembros asociados, comenzando por Chile y Bolivia. La otra dimensión se refiere a la ampliación de los objetivos políticos del Mercosur. La defensa de la democracia y los derechos humanos, junto con otros objetivos en el plano social, se fueron incorporando paulatinamente a la agenda, a la que se sumaban los países asociados."

6. Couto (2012, p. 13, traducción nuestra) recuerda que "América del Sur se convirtió en prioridad de la política externa brasileña en los años 2000. Al redefinir su referencia regional, sustituyendo a América Latina por su vecindad inmediata, Brasil adoptó el discurso de construcción del espacio sudamericano. El discurso fue seguido por una serie de iniciativas regionales que sugieren la existencia de un proyecto brasileño para América del Sur".
} 
En ese sentido, Granato (2014, p. 131, traducción nuestra) recuerda la formación de una "alianza estratégica” entre Brasil y Argentina, "motor, base o eje gravitacional de las diferentes etapas de integración en la región". Sobre esta premisa, afirma, "descansa la idea de que las concepciones integracionistas de Brasil y Argentina son las que 'moldearán', en el siglo XXI, la geometría del proceso de integración en América del Sur”?

A su vez, Jaguaribe (2008, p. 309-316, traducción nuestra) considera que

Argentina y Brasil tienen las condiciones para escapar del destino al que serían condenados de forma aislada, para convertirse en meros segmentos del mercado internacional y en provincias del "Imperio Americano". A partir de la formación de una alianza sólida, estable y confiable, sentarán las bases para la consolidación del Mercosur y la integración sudamericana, asegurando un gran destino histórico. Si no lo hacen, renunciarán a su identidad nacional y a cualquier rol histórico, convirtiéndose en mera geografía... La clave para la preservación de esa identidad nacional y la de otros países sudamericanos es la formación de una alianza sólida y confiable, entre Argentina y Brasil, a lo que Venezuela se suma lo antes posible. La Tríada A-B-V conducirá ciertamente a la consolidación del Mercosur y, en consecuencia, de la Comunidad Sudamericana de Naciones. ${ }^{8}$

Guimarães (2008, p. 59, traducción nuestra) presenta argumentos en el mismo sentido.

América del Sur está, necesaria e inevitablemente, en el centro de la política exterior brasileña. A su vez, el núcleo de la política brasileña en América del Sur está en el Mercosur. Y el núcleo de la política brasileña en el Mercosur debe ser sin duda Argentina. La integración entre Brasil y Argentina y su papel decisivo en América del Sur debe ser el objetivo más seguro, constante y vigoroso de las estrategias políticas y económicas tanto de Brasil como de Argentina. Cualquier intento de establecer prioridades diferentes para la política exterior brasileña, e incluso una

7. En cuanto a la preocupación por las asimetrías, Granato (2014, p. 138, traducción nuestra) señala que "en la misma fecha también se aprobó la Decisión CMC [Consejo del Mercado Común] ㄲo 28/2003, que establece que el Mercosur impulsará todas las negociaciones externas, con terceros y grupos de países, obteniendo un trato diferente para Paraguay, por su condición de menor economía y de país sin litoral; Decisión CMC nำ29/2003, que establece un régimen de origen diferenciado con miras a facilitar la ejecución de Paraguay de una política de industrialización orientada a la exportación; y Decisión CMC no 32/2003, que establece instrumentos diferenciados de política comercial para Paraguay y Uruguay".

8. El autor continúa: "Lo que está en juego en la relación entre Brasil y Argentina es el hecho de que una alianza argentino-brasileña sólida, confiable y estable ha constituido, en las condiciones actuales del mundo, un requisito sine qua non para la supervivencia histórica de ambos países. Ninguno de ellos tiene actualmente las condiciones para preservar aisladamente su soberanía efectiva y asegurar su identidad nacional y su destino histórico" (Jaguaribe, 2008, p. 300-301, traducción nuestra). A su vez, Barnabé (2013, p. 279, traducción nuestra) habla de un liderazgo colectivo de Argentina, Brasil y Venezuela (la ABV) "como una posibilidad real, a pesar de las diferencias entre los tres países, para la consolidación de un modelo de integración propio y autónomo en Suramérica". 
atención insuficiente a estos fundamentos, ciertamente tendrá graves consecuencias y correrá un grave riesgo de fracaso. ${ }^{?}$

En diciembre de 2004 fue realizada la III Reunión de los Presidentes de América del Sur en Cusco, Perú. Los acuerdos firmados exaltaran la identidad sudamericana, los valores comunes y una historia compartida. Según la declaración final, "el desarrollo de las regiones interiores del espacio sudamericano, contribuirá a profundizar el proyecto comunitario, así como a mejorar la calidad de vida de estas zonas que se encuentran entre las de menor desarrollo relativo" (CSN, 2004, p. 14). Entre las áreas de acción establecidas como prioritarias están la integración física (de transportes, energía y telecomunicaciones), los mecanismos financieros sudamericanos y el combate a las asimetrías. El documento emanado de ese encuentro habla de la formación de una Comunidad Sudamericana de Naciones. ${ }^{10}$

Así, la I Reunión de Jefes de Estado de la Comunidad Sudamericana de Naciones ocurrió en Brasilia, en septiembre de 2005. Entre sus principales resultados se encuentran la propuesta de estimular la convergencia de los Acuerdos de Complementación Económica (ACE) entre Mercosur, la Comunidad Andina de Naciones (CAN), Chile, Guyana y Surinam; así como la reafirmación de las áreas prioritarias definidas en Cusco. ${ }^{11}$ En noviembre de 2005, en la ciudad argentina de mar del Plata, tuvo lugar la IV Cumbre de las Américas, encuentro histórico que marcó el abandono de la propuesta del Área de Libre Comercio de las Américas (Alca). En diciembre de 2006, se realizó la reunión de Cochabamba, en Bolivia. La Declaración final del encuentro enuncia "un nuevo modelo de integración para el siglo XXI”, "ambicioso y preciso en sus objetivos estratégicos y, al mismo tiempo, flexible y gradual en su implementación” (CSN, 2006). ${ }^{12}$ También se consideraron fundamentales la profundización de acciones comunes

\footnotetext{
9. Bueno (2012, p. 57, traducción nuestra) también interpretó el acercamiento a Argentina como un elemento central: "Esta observación refuerza el hecho de que a lo largo de nuestra historia, las conversaciones sobre integración siempre han comenzado en Argentina, vista no solo como un socio preferido, pero también por la conciencia de su presencia e influencia entre los países de habla hispana, llevando a nuestras autoridades, desde Rio Branco a Janio Quadros, a darse cuenta de que nuestros intentos de aglutinación e influencia en el segmento sur del hemisferio serían ineficaces si no tuvieran la influencia compartida con el vecino del Plata".

10. Bandeira (2008, p. 28, traducción nuestra) recuerda que "Brasil, al fomentar, en la reunión de Cusco, el lanzamiento de la Comunidad Sudamericana de Naciones, después denominada Unión de Naciones Sudamericanas (Unasur), tuvo un objetivo estratégico, tratando de convertir no a sí mismo sino el conjunto de los países del subcontinente en una potencia mundial, no solo económica sino también política. Su dimensión sobrepasaba, de lejos, el carácter puramente comercial. Brasil no había renunciado al proyecto de convertirse en potencia mundial. Sin embargo, comprendió que el logro de tal objetivo pasaba por su integración con Argentina y, en una segunda etapa, con todos los demás países de América del Sur".

11. Disponible en: <http://www.iirsa.org/admin_iirsa_web/Uploads/Documents/rp_brasilia05_csn_declaracion_ sobre_integracion_en_\%20area_de_infraestructura.p̄df>.

12. Se reafirmaron, entre otros, los principios de "solidaridad y cooperación, en la búsqueda de mayor equidad reducción de la pobreza, reducción de asimetrías y fortalecimiento del multilateralismo"; " soberanía, respecto de la integridad territorial y la libre determinación de los pueblos, asegurando la prerrogativa de los Estados nacionales para decidir sus estrategias de desarrollo y su inserción internacional, sin injerencias externas en sus asuntos internos"; paz y solución pacífica de controversias; democracia y pluralismo; y derechos humanos (CSN, 2006).
} 
en las áreas de cooperación comercial, integración financiera y conexión industrial y productiva. ${ }^{13}$

La reunión de mayo 2008 marcó la fundación de Unasur. Su Tratado Constitutivo presenta entre sus fundamentos la promoción de "la integración financiera mediante la adopción de mecanismos compatibles con las políticas económicas y fiscales de los Estados-miembro" y "el desarrollo de mecanismos concretos y efectivos para la superación de las asimetrías, logrando así una integración equitativa” (Unasur, 2008). ${ }^{14}$ Además, la Unasur creó, en 2010, el Consejo Sudamericano de Economía y Finanzas (CSEF). ${ }^{15}$

De hecho, se promocionó la aproximación entre los Bancos Centrales de la región y surgieron propuestas para la integración monetaria y financiera, como el Banco del Sur, un Fundo Monetario del Sur, los intercambios con monedas locales y un mercado regional de títulos públicos. ${ }^{16}$ Las mismas fueron centralizadas en el Consejo Sudamericano de Economía y Finanzas configurando lo que se conoce como Nueva Arquitectura Financiera Regional (NAFR). Calixtre y Barros (2010, p. 22) sostienen que la NAFR tenía tres objetivos principales: disminuir la dependencia de los países sudamericanos con relación al dólar; reducir costos y facilitar la obtención de divisas para el comercio; y financiar el desarrollo económico de la región, buscando autonomía de los órganos financiadores tradicionales, como el Banco Interamericano de Desarrollo (BID) y el Banco Mundial. ${ }^{17}$

13. En abril de 2007 fue realizada la Cumbre Energética Sudamericana, en la Isla Margarita, en Venezuela. Entre los temas destacados estuvieron los planteamientos de construir el Gasoducto del Sur, de Caracas a Buenos Aires vía Brasilia, y de crear una organización regional de países exportadores de petróleo y gas. En la declaración final del encuentro se alteró el nombre Comunidad de Naciones Sudamericanas para Unión de Naciones Sudamericanas (Unasur) (CSN, 2007)

14. Medeiros (2010, p. 84) aprecia el acercamiento entre los países sudamericanos, pese a sus diferencias: "Con el inicio del nuevo milenio, las iniciativas que promueven la integración en Suramérica se han multiplicado. La propuesta de integración de Venezuela al Mercosur, la creación de la Unasur y la Alba han alcanzado una creciente importancia política y económica. Estas iniciativas de integración regional defienden propuestas que difieren de las implementadas por los Estados Unidos en Norte América, en América Central y el Caribe. También difieren de las que se han propuesto para todo el continente (el Área de Libre Comercio de las Américas) así como de los acuerdos bilaterales de libre comercio que Estados Unidos han firmado con países de la región como Chile, Colombia, Perú y del Caribe. Las iniciativas de integración sudamericanas tienden a crear una región integrada que posibilite un mayor poder de negociación para los países involucrados en negociaciones con el mundo desarrollado, y ofrezca la oportunidad de alcanzar un mayor nivel de cohesión social y económica".

15. Los objetivos del CSEF eran estimular el "uso de monedas locales y regionales en las transacciones comerciales intrarregionales", trabajar con "sistemas de pagos multilaterales y de crédito", crear un "mecanismo regional de garantías para facilitar el acceso a las diferentes formas de financiamiento", profundizar la "coordinación de los Bancos Centrales en relación a la gestión de las reservas internacionales", considerar la adopción de "mecanismos de coordinación de recursos financieros (...) para atender las demandas de proyectos de desarrollo e integración", impulsar un "mercado sudamericano financiero y de capitales", desarrollar "mecanismos de monitoreo conjunto para los flujos de capitales (...) en caso de crisis de balanza de pagos" y promocionar "mecanismos de coordinación de políticas macroeconómicas" (Severo, 2016).

16. Disponible en: <http://cadtm.org/IMG/article_PDF/article_2001.pdf>.

17. Briceño-Ruiz (2013, p. 14) interpreta que convivían en América Latina tres ejes de integración: el de integración abierta (formado por Chile, Colombia, México, Perú y casi toda Centroamérica), más alineado a Estados Unidos o pro-hegemónico; el revisionista (Argentina, Brasil, Paraguay y Uruguay), del Mercosur o antihegemónico; y el antisistémico (Bolivia, Cuba, Ecuador, Nicaragua y Venezuela), asociado al bloque bolivariano. Si eso es correcto, dicha división también existía dentro de Unasur y del Consejo Sudamericano de Economía y Finanzas, reproduciendo las distintas visiones y proposiciones. 
En el caso de los mecanismos regionales de financiamiento de corto plazo, se reforzaron los tradicionales Fondo Latinoamericano de Reservas (Flar) y el Convenio de Créditos y Pagos Recíprocos (CCR) de la Aladi y se crearon el Sistema de Monedas Locales (SML) del Mercosur y el Sistema Unificado de Compensación Regional de Pagos (Sucre) de la Alternativa Bolivariana para los Pueblos de Nuestra América (Alba). Con relación a los mecanismos regionales de financiamiento de largo plazo, igualmente se potencializaron los viejos instrumentos, como el BID, la Banco de Desarrollo de América Latina (CAF) y el Fonplata, y se plantearon nuevos como el Banco del Alba, el Banco del Sur y el Focem.

La revisión bibliográfica del proceso de institucionalización de la integración sudamericana en los años 2000 permite constatar la consolidación de una idea fuerza que asocia el acercamiento de los países con los empeños, principalmente de Brasil y Argentina, para reducir las grandes desigualdades regionales. En ese sentido, se puede decir que a lo largo de la década pasada se consolidaron tres principios básicos: i) existen grandes asimetrías, que deben ser enfrentadas; ii) el comercio desprovisto de restricciones y cuidados puede profundizar dichas asimetrías; y iii) la prosperidad de cada nación, sobre todo de las mayores, debe ser compartida con los vecinos. ${ }^{18}$

Asimismo, el periodo 2003-2010 quedó marcado por el aumento delos niveles de actividad económica en la región; por la ampliación de la interdependencia comercial entre Brasil y sus vecinos; y por la constitución de iniciativas políticas de consenso, impulsadas por Brasil. ${ }^{19}$ El sostén de estos resultados tiene como trasfondo el debilitamiento de la unipolaridad en el Sistema Internacional, la coincidencia de visiones pragmáticas por parte de las coaliciones de poder en los países sudamericanos y la marcada expansión de los precios internacionales de las commodities. La unión de esos componentes permitió los avances de la integración regional. Ese fue el contexto en el cual los países miembros del Mercosur

\footnotetext{
18. En 2005, según datos del Banco Mundial, la economía brasileña era 4,5 veces mayor que la argentina. La economía argentina era 11,5 veces mayor que la uruguaya. La economía uruguaya era 1,6 veces la de Paraguay. En el caso de la Unión Europea (UE), que incluye a 28 países, Alemania (la cuarta economía más grande del mundo) representaba el $20 \%$ del PIB. Francia, quinta en el ranking mundial, concentraba el $16 \%$ del producto interno bruto (PIB) de la UE. Esos números demuestran que las asimetrías entre el tamaño de las economías del Mercosur son mucho mayores que en la UE.

19. Medeiros (2010, p. 84) aprecia el acercamiento entre los países sudamericanos, pese a sus diferencias: "Con el inicio del nuevo milenio, las iniciativas que promueven la integración en Suramérica se han multiplicado. La propuesta de integración de Venezuela al Mercosur, la creación de la Unasur y la Alba han alcanzado una creciente importancia política y económica. Estas iniciativas de integración regional defienden propuestas que difieren de las implementadas por los Estados Unidos en Norte América, en América Central y el Caribe. También difieren de las que se han propuesto para todo el continente (el Área de Libre Comercio de las Américas) así como de los acuerdos bilaterales de libre comercio que Estados Unidos han firmado con países de la región como Chile, Colombia, Perú y del Caribe. Las iniciativas de integración sudamericanas tienden a crear una región integrada que posibilite un mayor poder de negociación para los países involucrados en negociaciones con el mundo desarrollado, y ofrezca la oportunidad de alcanzar un mayor nivel de cohesión social y económica".
} 
plantearon, en 2004, la creación de un fondo para la convergencia estructural. ${ }^{20}$ En 2006 el Focem se convirtió en la primera iniciativa importante dentro del Mercosur de cooperación para el desarrollo (Desiderá Neto, 2014, p. 58).

\section{FOCEM: INSTRUMENTO DEL MERCOSUR PARA LA REDUCCIÓN DE ASIMETRÍAS}

Los lineamientos generales adoptados por las instituciones tienden a reflejar el contexto histórico y político en el cual están insertadas. El Mercosur fue proyectado en los ańos 1980, durante la vigencia de un mundo desarrollista y bipolar, e instituido en los años 1990, en un tiempo de liberalismo y unipolaridad. Durante los años 2000 surgió la oportunidad de repensar el rol del bloque en un escenario marcado por el surgimiento de un mundo multipolar y de un renovado entusiasmo con las ideas de integración. Fueron rescatadas viejas reflexiones sobre la necesidad de tratamiento especial y diferenciado entre los países sudamericanos. ${ }^{21}$

Debido a las turbulencias del fin del siglo XX, comentadas en la sesión anterior, el inicio del milenio estimuló cambios de visión en los países del Mercosur, especialmente por parte de Brasil y Argentina. Las dos mayores economías se plantearon reformular las relaciones intrabloque, buscando disminuir las insatisfacciones de Paraguay y Uruguay, y dar un paso más hacia la reducción de las disparidades existentes. En ese sentido, el Estado brasileño desempeñó un papel fundamental con relación al tratamiento de las asimetrías. Guimarães (2008, p. 68, traducción nuestra) considera que

en un proceso de integración en que las asimetrías entre las partes son significativas se hacen indispensables programas específicos y ambiciosos para promocionar su reducción. Es indispensable la existencia de un proceso de transferencia de renta bajo la forma de inversiones entre los Estados participantes del esquema de integración. Ese proceso es todavía embrionario en Mercosur. Brasil debe estar dispuesto a conceder tratamiento más ventajoso sin reciprocidad a todos sus vecinos, en especial los de menor desarrollo relativo, los países mediterráneos y los países de menor PIB per cápita.

En diciembre de 2004, el CMC, órgano superior del Mercosur, sacó provecho de las buenas experiencias de mecanismos europeos de enfrentamiento

20. Es necesario tener en cuenta las conversaciones de los gobiernos de Paraguay y Uruguay con el de Estados Unidos sobre la posibilidad de firmar acuerdos de libre comercio, amenazando la existencia del Mercosur. Tessari (2012, p. 122, traducción nuestra) afirma que "eso hizo que el tema de los Fondos Estructurales estuviese cada vez más asociada a la estabilidad institucional del bloque. Así, esa se volvió una preocupación de los llamados 'socios mayores'".

21. La integración puede asumir caminos bastante distintos, con el riesgo de reproducir dentro de la región la lógica jerárquica del Sistema Internacional. Es decir, existe una bifurcación entre una "integración integradora", que se constituiría en un proyecto unificador y autonómico, o en una "integración desintegradora", que resultaría en un proyecto unificador pero de subordinación para alguna de las partes (Paradiso, 2009). A su vez, Medeiros (2010, p. 84) también habla de dos alternativas: "En primer lugar, el que aquí se denomina modelo neoliberal de integración pretende conseguir la integración de espacios económicos por medio del comercio libre. En segundo término, el que aquí se califica de modelo progresivo aspira a construir, por medio de políticas comerciales estratégicas y compensatorias, un espacio económico y social ampliado que permita incrementar el poder económico de las economías involucradas". 
a las asimetrías, como el Fondo Europeo de Desarrollo Regional (Feder), el Fondo Europeo de Orientación y Garantía Agrícola (Feoga) y el Fondo de Cohesión Social, que otorgan recursos a fondo perdido para los países menos desarrollados. Por medio de la Decisión CMC no 45/2004, ${ }^{22}$ se creó el Focem. Según el referido documento, el fondo tenía la finalidad de

financiar programas para impulsar la convergencia estructural, desarrollar la competitividad y promocionar la cohesión social, sobre todo en las economías más pequeñas de la región y en áreas menos desarrolladas; apoyar el funcionamiento de la estructura institucional y el fortalecimiento del proceso de integración. ${ }^{23}$

Con el objetivo de reducir las disparidades entre los países miembros e impulsar a las regiones con menor desarrollo relativo, principalmente en los países vecinos, Brasil insistió para que fuesen utilizados dos criterios: el primero tomó en consideración las diferencias de tamaño (PIB, territorio y población) entre las naciones, mientras el segundo atribuyó importancia a la desigualdad del PIB per cápita entre las regiones de los países. Así,

esa doble vinculación del concepto de asimetría es esencial para determinar el destino de los recursos. De hecho, por más grandes que sean las disparidades entre Brasil y Argentina ante los socios más pequeños, si el criterio para la distribución de los recursos fuese solamente el "tamaño" del país, las regiones de Brasil y Argentina con baja renta per cápita e IDH [índice de desarrollo humano] bajo no tendrían acceso al Focem. Problema semejante ocurriría caso los parámetros fuesen solamente los bajos niveles de renta per cápita e IDH de las regiones menos desarrolladas como normalmente ocurre en la Unión Europea. En ese caso, Paraguay y, sobre todo, Uruguay serían preteridos en la distribución de los recursos, ya que los índices referentes a esos dos criterios en regiones como el nordeste y el norte de Brasil están entre los peores del Mercosur. Por eso, la utilización de ambos parámetros se demuestra más apropiada para la realidad del bloque (Souza, Oliveira y Gonçalves, 2010, p. 28, traducción nuestra). ${ }^{24}$

22. La Decisión CMC no 27/2003 previó la conformación de fondos. Entre ellos, el Fondo de Promoción de Turismo del Mercosur; Fondo Financiamiento del Sector Educacional del Mercosur; Fondo Especial para Controversias; Fondo Mercosur de Garantías para Micro, Pequeñas y Medianas empresas; Fondo del Mercosur Cultural; Fondo de Agricultura Familiar del Mercosur; Fondo de Promoción de las Cooperativas del Mercosur. Disponible en: <https://focem.mercosur. int/uploads/normativa/DEC_027-2003_PT_Fundos\%20Estruturais-0.pdf>.

23. Disponible en: <https://focem.mercosur.int/uploads/normativa/DEC_045-2004_PT_FOCEM-3.pdf>.

24. Las comparaciones presentadas por los autores son esclarecedoras: "Al usar el criterio de la UE para caracterizar regiones de menor desarrollo relativo para el uso del Fondo Social Europeo (FSE) - tener el PIB per cápita inferior a $75 \%$ del promedio del bloque - tendríamos la siguiente configuración de la situación de las asimetrías al nivel de regiones: i) dos estados brasileños, Piauí y Maranhão, tienen PIB per cápita inferior al de Paraguay y una población de aproximadamente 10 millones de personas, superior a las poblaciones de Paraguay y Uruguay juntas; ii) de los 27 estados de Brasil, solamente cuatro (Rio Grande del Sur, São Paulo, Río de Janeiro y el Districto Federal) tienen el PIB per cápita superior al de Uruguay; iii) la ciudad de Buenos Aires tiene el PIB per cápita dos veces superior al del Districto Federal, el mayor de Brasil, y tres veces superior al estado de Sao Paulo; y iv) de las regiones con PIB per cápita inferior al $75 \%$ del promedio para el Mercosur, nueve son de Argentina y 16 de Brasil, además de Paraguay" (Souza, Oliveira y Gonçalves, 2010, p. 28, traducción nuestra). 
Las normas para promocionar el funcionamiento del Focem fueron instituidas por la Decisión CMC no 18/2005, en junio de 2005. El documento establece los cuatro programas del fondo: I. Convergencia Estructural; II. Desarrollo y Competitividad; III. Cohesión Social; y IV. Fortalecimiento de la Estructura Institucional y del Proceso de Integración. El primer programa está relacionado con financiamientos para infraestructura física, como pasos de frontera, electricidad, saneamiento, carreteras y ferrocarriles. El segundo tiene la finalidad de aumentar la competitividad y productividad de los miembros del Mercosur y, también, de favorecer asociaciones estratégicas, instigar la investigación y el desarrollo de nuevos productos.

El tercer programa fomenta el desarrollo social por medio de la promoción de las áreas como educación, empleo, salud y reducción de la pobreza. Por último, el cuarto programa tiene el objetivo de reforzar la estructura institucional del Mercosur y los procesos de integración regional. Las normas fundacionales del Focem previeron la priorización de recursos para el Programa I, atribuyendo recursos exclusivamente para obras de infraestructura durante los primeros cuatro años. ${ }^{25}$ También quedó establecido que el fondo tendría vigencia de diez ańos; es decir, en 2015, podría ser renovado desde que fuese la voluntad de los Estados-parte. La misma Decisión CMC nº 18/2005 determinó que "en el primer año presupuestario los Estados-parte integrarán el 50\% de sus contribuciones anuales para implementar proyectos piloto. En el segundo año presupuestario, integrarán el 75\%. A partir del tercer año, integrarán el 100\% de sus aportaciones anuales". ${ }^{26}$

Los recursos del Focem tenían como origen los aportes regulares anuales de los Estados-miembro del Mercosur, los aportes voluntarios con asignación específica y las contribuciones de terceros países, de instituciones o de organismos internacionales. Los aportes regulares eran realizados dos veces al año, hasta el mes de abril la primera parte y hasta octubre lo correspondiente a la segunda. Además, el fondo podría acceder a recursos resultantes de cuentas remuneradas. ${ }^{27}$ Se definió que los financiamientos tienen carácter no reembolsable, o sea, son donaciones a fondo perdido y no préstamos que necesitan ser devueltos. Los aportes regulares de los países miembros deberían sumar US\$100 millones

25. Para Reis (2017), secretario de comunicación social del Parlamento Sudamericano (Parlasur), "los proyectos del Focem continuarán enfocando más en cuestiones de infraestructura. Incluso porque eso pasa con la mayoría de los fondos de crédito multilateral que invierten en la región. El déficit de infraestructura que tenemos es inmenso y eso dificulta el desarrollo y el crecimiento económico. Si tenemos una buena conexión entre el Atlántico y Pacífico, por ejemplo, las empresas podrán exportar para Asia usando esos corredores bioceánicos, aumentando sus exportaciones y el empleo. Es decir, el programa I también tiene impacto en el área social".

26. Disponible en: <https://focem.mercosur.int/uploads/normativa/DEC_018-2005_PT_FERR_IntegFuncFOCEM-2.pdf>. 27. El análisis de los Presupuestos Anuales del Focem, entre 2008 y 2020, permite constatar que los ingresos por medio de "intereses generados" crecieron de manera exponencial: de US\$ 143 mil en 2009 para US\$1,3 millón en 2015 y para US\$3,9 millones en 2020. Dicho crecimiento es resultado directo de los rendimientos del dinero no usado. 
anuales y cada país sería responsable por contribuir con porcentajes establecidos a partir del promedio histórico de su participación en el PIB de Mercosur entre 1995 y 1998. Se definió que Brasil depositaría el 70\% del monto total, Argentina el 27\%, Uruguay el $2 \%$ y Paraguay el $1 \%$.

Con relación a la distribución de los recursos entre los Estados-parte, se estableció una lógica inversa, con la finalidad de privilegiar a las economías más pequeñas. Los proyectos presentados por Paraguay recibirían el $48 \%$ de los recursos; Uruguay, el 32\%; Argentina y Brasil, el 10\% cada uno, según datos del Mercosur de 2005. Con el ingreso de Venezuela al Mercosur, en 2012, se determinó que el nuevo miembro sería responsable por contribuir con US\$27 millones anuales para el Focem. ${ }^{28}$ El fondo pasaría a contar, de esa manera, con US\$ 127 millones anuales. $^{29}$

En el proceso de selección, los proyectos cumplían trámites de aprobación en los distintos órganos del Mercosur. ${ }^{30}$ Cada Estado era responsable por someter propuestas según su cuota disponible de recursos. Además, dos o más Estados podían presentar el mismo proyecto en conjunto, configurando una iniciativa pluriestatal. El procedimiento para el envío de propuestas se daba por medio de comunicación conjunta de las Unidades Técnicas Nacionales (UTN) de cada país. Si todos los requisitos técnicos exigidos fuesen cumplidos cualquier entidad pública de los países miembros podría solicitar y obtener acceso a los recursos del Focem.

De esa manera, provincias y municipios tenían condiciones de presentar sus planes directamente a la UTN, sin necesidad de mediación de los gobiernos nacionales. En ese punto reside la importancia de creación del Foro Consultivo de Municipios, Estados Federados, Provincias y Departamentos del Mercosur (FCCR), en 2004 (Decisión CMC no 41/2004). ${ }^{31}$ La liberación de recursos estaba condicionada al cumplimiento de etapas de las obras o iniciativas, que eran acompańadas por los órganos de seguimiento y control; y posteriormente sometidos a revisiones por parte de auditorías externas. Asimismo, los Estados

\footnotetext{
28. Disponible en: <http://www.sice.oas.org/trade/mrcsrs/decisions/DEC_041_2012_s.pdf>.

29. La asignación de recursos también sufrió cambios y fue establecida en $43,65 \%$ para Paraguay, 29,05\% para Uruguay y $9,1 \%$ para Argentina, para Brasil y para Venezuela. Ante la crisis del país caribeño y su posterior suspensión del bloque, solo logró enviar aportes en 2014 y 2015, sin haber solicitado recursos para ningún proyecto.

30. "Si cumple los objetivos del Focem - reducción de asimetrías regionales o fortalecimiento del proceso de integración; si se ajusta a uno de los cuatro programas del Focem; si cumple con los requisitos de presentación: oportunidad, forma y documentación; si es propuesto y ejecutado bajo responsabilidad del sector público de uno o más Estados-parte; si los gastos son superiores a US\$ 500 mil (excepto el Programa IV); si la tasa de retorno socioeconómico es superior a la tasa mínima de rentabilidad social; si no sustituye a otros proyectos en ejecución o gastos estructurales públicos del Estado-parte beneficiario; si optimiza la utilización de los recursos naturales y prevé acciones de mitigación de daños ambientales; si demuestra haber tomado en cuenta las especificidades culturales, geográficas, económicas y sociales del territorio" (Focem, 2015, p. 5).

31. Disponible en: <http://www.sice.oas.org/Trade/MRCSRS/Decisions/dec4104s.asp>.
} 
deberían comprometerse a garantizar por lo menos el 15\% del monto total de cada proyecto a ser desarrollados en su territorio.

Según la página electrónica oficial de Focem, durante los quince años iniciales de su existencia, entre 2006 y 2020, fueron aprobados 53 proyectos, con más de US\$ 1.100 millones del propio fondo y otros US\$ 617 millones oriundos de otras fuentes (BID y CAF, entre otros). Al considerarse solamente los programas I, II y III, son 44 proyectos nacionales y tres plurinacionales, con más de US\$ 1.030 millones del Focem. Las iniciativas plurinacionales alcanzaron los US\$ 27,5 millones mientras las acciones del Programa IV, ${ }^{32}$ de Fortalecimiento de la Estructura Institucional y de la Integración, absorbieron seis proyectos, sumando US\$1,4 millón.

La tabla 1 revela que los recursos del Focem invertidos en el Programa I alcanzan los US\$1.012,6 millones, equivalentes al 91,9\% del total. El Programa II recibió US\$ 46,7 millones, un 4,2\% de los recursos totales del fondo. A su vez, el Programa III cuenta con US\$ 42,4 millones, un 3,8\%. Al observar la distribución de recursos del Focem por país, los resultados fueron los siguientes: más del 92,3\% se dirigieron para Paraguay (66,8\% del total) y Uruguay (25,5\%). Por otra parte, los mayores financiadores del mecanismo recibieron la menor parte del dinero; Argentina $(4,2 \%)$ y Brasil $(0,9 \%) .{ }^{33}$

\section{TABLA 1}

Focem: aportes de los Programas I, II y III, por país (2006-2020)

(En US\$ millones)

\begin{tabular}{|c|c|c|c|c|c|c|c|c|c|c|c|c|c|c|c|}
\hline & \multicolumn{3}{|c|}{ Argentina } & \multicolumn{3}{|c|}{ Brasil } & \multicolumn{3}{|c|}{ Paraguay } & \multicolumn{3}{|c|}{ Uruguay } & \multicolumn{3}{|c|}{ Total } \\
\hline & Focem & Locales & Total & Focem & Locales & Total & Focem & Locales & Total & Focem & Locales & s Total & Focem & Locales & Total \\
\hline I & 23,7 & 10,5 & 34,3 & 4,5 & 1,6 & 6,1 & 705,7 & 384,1 & $1.089,9$ & 272,9 & 197,4 & 470,3 & $1.012,6$ & 5593,7 & $1.606,3$ \\
\hline II & 0,6 & 0,1 & 0,7 & 5,8 & 1,8 & 7,6 & 14,3 & 4,3 & 18,6 & 4,2 & 1,0 & 5,3 & 46,7 & 7,2 & 53,9 \\
\hline III & 22,5 & 12,1 & 34,6 & 0,0 & 0,0 & 0,0 & 15,7 & 3,6 & 19,3 & 4,2 & 0,8 & 5,0 & 42,4 & $4 \quad 16,6$ & 58,9 \\
\hline Total & 46,8 & 22,8 & 69,6 & 10,3 & 3,4 & 13,7 & 735,7 & 392,0 & $1.127,8$ & 281,3 & 199,2 & 480,6 & $1.101,6$ & 6617,5 & $1.719,1$ \\
\hline
\end{tabular}

Fuente: Focem.

Elaboración de los autores.

En la siguiente tabla se identifica la cantidad de proyectos de cada programa por país. En el caso del Programa I, de Convergencia Estructural, se nota que 23 de los 27

32. Los proyectos que corresponden al Programa IV suman cerca del $0,13 \%$ de los recursos del Focem y son presentados por medio del propio Mercosur. Las acciones existentes en esa área fueron solicitadas por el Instituto de Políticas Públicas en Derechos Humanos del Mercosur (IPPDH) y por la Secretaría del Mercosur.

33. Cruz (2019, p. 50, traducción nuestra) afirma que "obviamente, los miembros más pequeños son los que más necesitan de fomento a la infraestructura, pero hay regiones ubicadas en los países líderes del Mercosur (Brasil y Argentina) que carecen de ese tipo de financiamiento, como es el caso del interior del Nordeste brasileño. Por tanto, observando la complejidad regional del Mercosur y las particularidades de cada país, se concluye que a pesar de la contribución del Focem para la integración regional del bloque, la escasez de recursos disponibles y los criterios territoriales para la selección de los proyectos necesitan ser discutidos y mejorados". 
proyectos están ubicados en Paraguay (12) y Uruguay (11). Los dos países también concentran 6 de los 11 proyectos del Programa II y 6 de los 9 del Programa III. Se constata que, de hecho, los recursos del Focem fueron destinados principalmente para el financiamiento de iniciativas en las dos economías menores. Paraguay (19) y Uruguay (16) tuvieron 35 proyectos aprobados, mientras Brasil posee 5 y Argentina 4.

TABLA 2

Situación de los proyectos por Programa I, II y III (2006-2020)

\begin{tabular}{lcccccc}
\hline & Argentina & Brasil & Paraguay & Uruguay & Pluri & Total \\
\hline I. Convergencia Estructural & 1 & 2 & 12 & 11 & 1 & $\mathbf{2 7}$ \\
En ejecucióhn & 0 & 0 & 4 & 5 & 1 & $\mathbf{1 0}$ \\
Finalizados & 1 & 2 & 8 & 6 & 0 & $\mathbf{1 7}$ \\
\hline II. Desarrollo y Competitividad & 1 & 2 & 4 & 2 & 2 & $\mathbf{1 1}$ \\
En ejecución & 0 & 2 & 1 & 0 & 1 & $\mathbf{4}$ \\
Finalizados & 1 & 0 & 3 & 2 & 1 & $\mathbf{7}$ \\
\hline III. Cohesión Social & 2 & 1 & 3 & 3 & 0 & $\mathbf{9}$ \\
$\quad$ En ejecución & 1 & 0 & 1 & 0 & 0 & $\mathbf{2}$ \\
$\quad$ Finalizados & 1 & 1 & 2 & 3 & 0 & $\mathbf{7}$ \\
\hline En ejecución & 1 & 2 & 6 & 5 & 2 & $\mathbf{1 6}$ \\
Finalizados & 3 & 3 & 13 & 11 & 1 & $\mathbf{3 1}$ \\
Total & $\mathbf{4}$ & $\mathbf{5}$ & 19 & $\mathbf{1 6}$ & $\mathbf{3}$ & $\mathbf{4 7}$ \\
\hline
\end{tabular}

Fuente: Focem.

Elaboración de los autores.

Con relación al avance de los 47 proyectos de los Programas I, II y III, hay 31 finalizados y 16 en ejecución. ${ }^{34}$ Los ya concluidos suman 17 de los 27 del Programa I, 7 de los 11 del Programa II y 7 de los 9 del Programa III. Al observar por país, fueron finalizados 13 en Paraguay, 11 en Uruguay, 3 en Brasil y 3 en Argentina. Vale decir que 10 entre todos los 47 proyectos forman parte de la cartera de IIRSA ( 5 en Uruguay, 4 en Paraguay y 1 en Argentina). A continuación, serán presentados los 53 proyectos: 44 nacionales, 3 plurinacionales y 6 del Programa IV.

$\mathrm{Al}$ analizar los proyectos de Paraguay, en la tabla 3, se verifica que 11 de los 18 corresponden al Programa I, con la pavimentación de rutas, construcción de saneamiento y conexiones eléctricas. Las iniciativas que más recibieron recursos fueron la construcción de la línea de transmisión 500 kV Itaipú-Villa Hayes, de

34. Según la página web del Focem, hay cuatro proyectos de Uruguay con fecha de actualización en junio de 2020 con avance superior al $99 \%$. Además, hay cuatro proyectos que tuvieron sus contratos rescindidos: Biblioteca de la Universidad de Integración Latinoamericana (Unila) y del Instituto Mercosur de Estudios Avanzados (Imea) en Foz de Iguazú (Brasil); Obras de Ingeniería del Sistema de Saneamiento de la Ciudad de Sao Borja (Brasil); Pymes exportadoras de Bienes de Capital (Argentina) y construcción de la Autopista Ñu Guazú-Asunción-Luque (Paraguay). Para facilitar la exposición, esos cuatro proyectos fueron considerados "finalizados". 
la subestación Villa Hayes y de la ampliación de la subestación Margen Derecha Itaipú, con US\$ 400 millones aportados por Focem y US\$155 millones de fuentes locales. Esa obra es parte de cartera de la IIRSA y representa más de $62 \%$ de los montos aportados por el fondo para Paraguay. La acción amplió las posibilidades para la generación de polos industriales en el interior del país, además de permitir incrementar los intercambios de energía con Argentina.

TABLA 3

Focem: proyectos aprobados en Paraguay (En US\$ millones)

\begin{tabular}{|c|c|c|c|}
\hline Proyectos & Aporte del Focem & Aporte local & Total \\
\hline \multicolumn{4}{|l|}{ I. Convergencia Estructural } \\
\hline $\begin{array}{l}\text { Construcción de la avenida Costanera Norte de Asunción - 2a etapa y conexión } \\
\text { (avenida Primer Presidente) con la Ruta Nacional no } 9\end{array}$ & 83,24 & 33,36 & 116,60 \\
\hline $\begin{array}{l}\text { Construcción de la línea de transmisión } 500 \text { kV Itaipú-Villa Hayes, de la subestación } \\
\text { Villa Hayes y de ampliación de la subestación Margen Derecha Itaipú (finalizado) }\end{array}$ & 400,00 & 155,00 & 555,00 \\
\hline Rehabilitación y pavimentación asfáltica del tramo Concepción-Puerto Vallemi (finalizado) & 75,31 & 84,99 & 160,30 \\
\hline $\begin{array}{l}\text { Recapado del tramo alimentador de las Rutas } 1 \text { y 6, corredores de integración } \\
\text { regional, Ruta } 1 \text { (Carmen del Paraná)-La Paz, Ruta Graneros del Sur (finalizado) }\end{array}$ & 3,09 & 0,91 & 4,00 \\
\hline $\begin{array}{l}\text { Pavimentación asfáltica sobre empedrado del tramo alimentador de la Ruta } \\
\text { 2, corredor de integración regional, Itacurubi de la Cordillera-Valenzuela-Gral. } \\
\text { Bernardino Caballero (finalizado) }\end{array}$ & 4,01 & 1,18 & 5,19 \\
\hline $\begin{array}{l}\text { Pavimentación asfáltica sobre empedrado del tramo alimentador de las Rutas } 6 \text { y } 7 \text {, } \\
\text { corredores de integración regional, Pdte. Franco-Cedrales (finalizado) }\end{array}$ & 4,52 & 1,57 & 6,09 \\
\hline $\begin{array}{l}\text { Pavimentación asfáltica sobre empedrado del tramo alimentador de la Ruta 8, corredor de } \\
\text { integración regional, Ruta 8-San Salvador-Borja Iturbe y ramal a Rojas Potrero (finalizado) }\end{array}$ & 4,90 & 3,29 & 8,19 \\
\hline $\begin{array}{l}\text { Construcción y mejoramiento de sistemas de agua potable y saneamiento básico en } \\
\text { pequeñas comunidades rurales e indígenas del país }\end{array}$ & 10,61 & 9,73 & 20,34 \\
\hline Rehabilitación de corredores viales - trecho Concepción-Pozo Colorado (finalizado) & 14,44 & 22,85 & 37,29 \\
\hline $\begin{array}{l}\text { Rehabilitación y mejoramiento de carreteras de acceso y circunvalación del Gran } \\
\text { Asunción (finalizado) }\end{array}$ & 12,63 & 8,55 & 21,18 \\
\hline Construcción de la Autopista Ñu Guazú: Asunción -Luque (6,3km) (rescindido) & - & - & - \\
\hline Mejoras en la conectividad física del Departamento de San Pedro & 92,99 & 62,72 & 155,71 \\
\hline \multicolumn{4}{|l|}{ II. Desarrollo y Competitividad } \\
\hline Desarrollo Tecnológico, Innovación y Evaluación de la Conformidad - DeTIEC (finalizado) & 5,00 & 1,47 & 6,47 \\
\hline $\begin{array}{l}\text { Desarrollo de productos turísticos competitivos en la Ruta Turística Integrada Iguazú } \\
\text { Misiones, atractivo turístico del Mercosur (finalizado) }\end{array}$ & 0,99 & 0,31 & 1,31 \\
\hline Laboratorio de Bioseguridad y Fortalecimiento del Laboratorio de Control de Alimentos & 4,08 & 1,18 & 5,26 \\
\hline Programa de apoyo integral a microempresas (finalizado) & 4,25 & 1,34 & 5,59 \\
\hline \multicolumn{4}{|l|}{ III. Cohesión Social } \\
\hline $\begin{array}{l}\text { Mercosur Yporã: promoción de acceso al agua potable y saneamiento básico en } \\
\text { comunidades en situación de pobreza y extrema pobreza (finalizado) }\end{array}$ & 0,67 & 1,40 & 2,07 \\
\hline Mercosur Roga & 7,50 & 2,21 & 9,71 \\
\hline $\begin{array}{l}\text { Mercosur Hábitat de Promoción Social, Fortalecimiento de Capital Humano y Social } \\
\text { en asentamientos en condiciones de pobreza (finalizado) }\end{array}$ & 7,50 & - & - \\
\hline Total & 735,74 & 392,05 & $1.120,29$ \\
\hline
\end{tabular}

Fuente: Focem.

Elaboración de los autores.

Hay obras fundamentales para la integración nacional de Paraguay y su proyección hacia los países vecinos, como la rehabilitación del tramo entre 
Concepción y Pozo Colorado y la pavimentación de $170 \mathrm{~km}$ la carretera entre Concepción y Vallemí, cerca de la frontera con Brasil, donde está ubicada la Industria Nacional del Cemento e importantes yacimientos de caliza. También son financiados proyectos de construcción de casas populares en regiones de extrema pobreza y programas de capacitación para comunidades históricamente excluidas.

Buena parte de los proyectos adquirió un estatus de credibilidad y relevancia por el solo hecho de formar parte de la cartera de Focem, lo que les permitió obtener recursos por medio de fuentes externas. Además de la referida rehabilitación y pavimentación asfáltica del tramo Concepción-Puerto Vallemi, se pueden citar otros como la construcción y mejoramiento de sistemas de agua potable y saneamiento básico en pequeñas comunidades rurales e indígenas del país, con US $\$ 10,6$ millones del fondo y US\$ 9,7 de origen local. De igual forma, la rehabilitación de corredores viales contó con US\$14,4 millones del Focem y US\$22,8 millones provenientes de fuentes locales. En diciembre de 2018, Paraguay tuvo un nuevo proyecto aprobado, para mejoras en la conectividad física del Departamento de San Pedro, con un monto de US\$92,9 millones del Focem y más US\$ 62,7 millones de otras fuentes. Se trata de la obra la construcción y rehabilitación de más de $120 \mathrm{~km} \mathrm{de}$ carreteras para impulsar el desarrollo socioeconómico a sureste del departamento de Concepción, que hacen la frontera con Mato Grosso del Sur, en Brasil.

TABLA 4

Focem: proyectos aprobados en Uruguay

(En US\$ millones)

\begin{tabular}{|c|c|c|c|}
\hline Proyectos & $\begin{array}{l}\text { Aporte del } \\
\text { Focem }\end{array}$ & $\begin{array}{l}\text { Aporte } \\
\text { local }\end{array}$ & Total \\
\hline \multicolumn{4}{|l|}{ I. Convergencia Estructural } \\
\hline Rehabilitación de la Ruta 30 - tramo IV: Javier de Viana-Arroyo Chiflero, Departamento de Artigas & 6,53 & 3,64 & 10,17 \\
\hline $\begin{array}{l}\text { Rehabilitación de la Ruta } 30 \text { - tramo III: Tomás Gomensoro-Acceso Oeste Arroyo Cuaró, } \\
\text { Departamento de Artigas }\end{array}$ & 7,98 & 4,45 & 12,43 \\
\hline $\begin{array}{l}\text { Rehabilitación de la Ruta } 30 \text { - tramo II: Tomás Gomensoro-Acceso Oeste Arroyo Cuaró, } \\
\text { Departamento de Artigas }\end{array}$ & 7,63 & 4,26 & 11,88 \\
\hline $\begin{array}{l}\text { Rehabilitación de la Ruta } 30 \text { - tramo I, ramal: Acceso Este Arroyo Cuaró-Javier de Viana, } \\
\text { Departamento de Artigas }\end{array}$ & 3,63 & 2,00 & 5,63 \\
\hline Rehabilitación de la Ruta 8 - Treinta y Tres-Melo/tramo II: km 366 al km 393,1 (finalizado) & 11,11 & 4,56 & 15,67 \\
\hline Rehabilitación de la Ruta 8 - Treinta y Tres-Melo/tramo I: km 310 al km 338 (finalizado) & 11,04 & 4,54 & 15,59 \\
\hline Rehabilitación de vía férrra II; tramos Piedra Sola-Tres Árboles-Algorta-Paysandú-Salto-Salto Grande & 83,52 & 43,78 & 127,30 \\
\hline Rehabilitación de vía ferrea, línea Rivera: tramo Pintado (km 144) -Frontera (km 566) (finalizado) & 50,10 & 24,73 & 74,83 \\
\hline Ruta 12: tramo Empalme Ruta 54-Ruta 55 (finalizado) & 2,93 & 1,44 & 4,37 \\
\hline Ruta 26 - tramo Melo: Arroyo Sarandi de Barceló (finalizado) & 5,31 & 2,62 & 7,93 \\
\hline Interconexión eléctrica de 500 mw Uruguay-Brasil (finalizado) & 83,11 & 101,36 & 184,47 \\
\hline \multicolumn{4}{|l|}{ II. Desarrollo y Competitividad } \\
\hline Internacionalización de la especialización productiva (2a etapa) (finalizado) & 2,97 & 0,78 & 3,75 \\
\hline $\begin{array}{l}\text { Internacionalización de la especialización productiva - desarrollo y capacitación tecnológica de los } \\
\text { sectores de software, biotecnología y electrónica y sus respectivas cadenas de valor (finalizado) }\end{array}$ & 1,28 & 0,23 & 1,50 \\
\hline
\end{tabular}


III. Cohesión Social

Intervenciones múltiples en asentamientos ubicados en territorios de frontera con situaciones de extrema pobreza y emergencia sanitaria, ambiental y hábitat (finalizado)

Desarrollo de capacidades e infraestructura para clasificadores informales de residuos urbanos en localidades del interior del Uruguay (finalizado)

Fuente: Focem.

Elaboración de los autores.

Con relación a Uruguay, el proyecto rehabilitación de vías férreas II, tramos Piedra Sola-Tres Árboles-Algorta-Paysandú, Queguay-Salto-Salto Grande es el segundo mayor de todos los proyectos financiados por el Focem, con un aporte de US\$ 83,5 millones. La iniciativa fue aprobada en 2012 y las obras de reconstrucción de 327 km de vías empezaron en 2016. Esa vía es de gran relevancia para el Mercosur por estar integrada a la interconexión ferroviaria Paraguay-Argentina-Uruguay y a la construcción y rehabilitación de la ferrovía Asunción-Posadas.

A su vez, la obra de rehabilitación de vía férrea tramo Pintado-Rivera, de $422 \mathrm{~km}$, fue modificado para Paso de los Toros-Rivera, con $273 \mathrm{~km}$. La reforma anunciada en 2009 fue concluida en 2018 con financiamiento total de casi US\$ 75 millones. Actualmente esta línea conecta el departamento de Durazno, a $260 \mathrm{~km}$ de Montevideo, con la ciudad de Rivera, que se encuentra en la frontera con Río Grande del Sur, Brasil. Igualmente vale destacar el proyecto interconexión eléctrica de 500 mw Uruguay-Brasil, también finalizado, que contó con inversiones de US\$184,4 millones. Entre sus beneficios están la creación de posibilidades de complementación energética.

El caso uruguayo, así como el paraguayo, revela el papel destacado del Focem como afianzador de importantes iniciativas de integración. El fondo aprobó US\$ 281,3 millones para proyectos en el país y, al mismo tiempo, potencializó aportes de otras fuentes que superan los US\$ 480,5 millones. Es decir, además de los recursos garantizados por el Focem, hay otros US\$ 200 millones aportados por entes locales. Los resultados positivos son evidentes. ${ }^{35}$ De los 16 proyectos desarrollados en Uruguay, 11 ya fueron finalizados y los que faltan son de infraestructura. Cuatro de ellos son tramos de la Ruta 30 (dos en condiciones

35. Ríos (2017), técnica sénior y coordinadora del Focem, afirma: "Es un fondo pequeño cuando se lo compara con otros. No son fondos con los cuales se pueda hacer un mega puerto comercial en uno de los Estados-parte. Pero si nosotros nos centramos en atender poblaciones con objetivos que sean estratégicos para cada país, creo que se pueda hacer cosas buenas". Aunque se hable de la limitación de los recursos, los datos demuestran que los aportes anuales no han sido utilizados plenamente. El hecho de que haya dinero y falten proyectos sugiere la necesidad de correcciones en los procedimientos. Una de las posibilidades sería autorizar el uso de los recursos del Focem para "elaboración de estudios de viabilidad y proyectos básicos", lo que era impedido por la Decisión CMC no 1/2010. Disponible en: $<$ https://focem.mercosur.int/uploads/normativa/DEC_001-2010_PT_FERR1_Regulamento\%20FOCEM-6.pdf>. 
bastante adelantadas) y el último es la ya comentada vía férrea entre Tres Árboles y Salto, en la frontera con Argentina.

TABLA 5

Focem: proyectos aprobados en Argentina

(En US\$ millones)

\begin{tabular}{|c|c|c|c|}
\hline Proyectos & $\begin{array}{l}\text { Aporte del } \\
\text { Focem }\end{array}$ & $\begin{array}{l}\text { Aporte } \\
\text { local }\end{array}$ & Total \\
\hline \multicolumn{4}{|l|}{ I. Convergencia Estrutural } \\
\hline Vínculo de interconexión en 132 kV. ET Iberá-ET Paso de los Libres Norte (finalizado) & 23,72 & 10,53 & 34,25 \\
\hline \multicolumn{4}{|l|}{ II. Desarroollo y Competitividad } \\
\hline $\begin{array}{l}\text { Pymes exportadoras de bienes de capital, plantas llave en mano y servicios de ingeniería (rescindido } \\
\text { en 2019) }\end{array}$ & 0,55 & 0,12 & 0,67 \\
\hline \multicolumn{4}{|l|}{ III. Cohesión Social } \\
\hline $\begin{array}{l}\text { Polo de Desarrollo Local y Regional - Universidad Nacional Arturo Jauretche (Unaj) - Partido } \\
\text { Florencio Varela }\end{array}$ & 13,95 & 8,00 & 21,95 \\
\hline $\begin{array}{l}\text { Intervenciones integrales en los edificios de enseñanza obligatoria en los Departamentos General } \\
\text { Obligado, Vera, } 9 \text { de Julio, Garay y San Javier - Provincia de Santa Fe (finalizado) }\end{array}$ & 8,55 & 4,13 & 12,68 \\
\hline Total & 46,77 & 22,78 & 69,56 \\
\hline
\end{tabular}

Fuente: Focem.

Elaboración de los autores.

Los aportes del Focem para proyectos en Argentina alcanzan los US \$ 46,7 millones y los montos totales movilizados llegaron a US\$ 69,5 millones. Pese al hecho de que la mayoría de las iniciativas financiadas son en el área de Desarrollo y Competitividad, la acción que recibió más recursos fue el vínculo de interconexión en $132 \mathrm{kV}$ ET Iberá-ET Paso de los Libres Norte. Ese proyecto, concluido en 2014, es el único de Argentina en el área de Convergencia Estructural, con US\$23,7 millones de aportes del fondo y otros US\$10,5 millones de fuentes locales. Según las informaciones relativas a la obra, el tramo de $70 \mathrm{~km}$ posibilita la interconexión con el corredor del río Uruguay y el cierre del anillo energético. Igualmente se destaca el Polo de Desarrollo en la Unaj - Florencio Varela, con recursos que ascienden a los US\$13,9 millones más US\$ 8 millones de origen local. El proyecto "Pymes exportadoras de bienes de capital, plantas llave en mano y servicios de ingeniería”, que sumaba US\$ 552,5 mil, fue el único de todos los cuatro rescindidos que llego a empezar. Se trataba de mejorar la performance 
exportadora de 300 pequeñas y medianas empresas argentinas. Ahora solo quedaría un proyecto del Focem en ejecución en el país.

TABLA 6

Focem: proyectos aprobados en Brasil

(En US\$ millones)

\begin{tabular}{|c|c|c|c|}
\hline Proyectos & $\begin{array}{l}\text { Aporte del } \\
\text { Focem }\end{array}$ & $\begin{array}{l}\text { Aporte } \\
\text { local }\end{array}$ & Total \\
\hline \multicolumn{4}{|l|}{ I. Convergencia Estructural } \\
\hline Obras de ingeniería del sistema de saneamiento de la ciudad de São Borja/Rio Grande del Sur (rescindido) & - & - & - \\
\hline Ampliación del Sistema de Saneamiento de Ponta Porã/Mato Groso del Sur (finalizado) & 4,50 & 1,64 & 6,14 \\
\hline \multicolumn{4}{|l|}{ II. Desarrollo y Competitividad } \\
\hline Calificación de proveedores de la cadena productiva de petróleo y gas & 2,85 & 0,82 & 3,67 \\
\hline Intensificación y complementación automotriz en el ámbito del mercosur & 2,96 & 0,97 & 3,93 \\
\hline \multicolumn{4}{|l|}{ II. Desarrollo y Competitividad } \\
\hline $\begin{array}{l}\text { Proyecto de Implementación de la Biblioteca Unila-Biunila y del Imea, de la Universidad Federal } \\
\text { de Integración Latinoamericana (Unila) en la región trinacional en Foz de Iguazú, en el Estado de } \\
\text { Paraná, Brasil (rescindido) }\end{array}$ & - & - & - \\
\hline Total & 10,31 & 3,43 & 13,74 \\
\hline
\end{tabular}

En el caso de Brasil, originalmente había cinco proyectos, pero dos fueron rescindidos: la biblioteca de la Unila y las obras de saneamiento en la ciudad de Sao Borja, en la frontera con Argentina. El principal proyecto, la ampliación del sistema de saneamiento en Ponta Porã, frontera con Paraguay, está finalizado. Se trató de una inversión de US\$ 4,5 millones del Focem y otro US\$1,6 millón provino de fuentes locales. Esa obra incluyó la construcción de $94 \mathrm{~km}$ de red de alcantarillado y casi 4.000 conexiones domiciliarias. Quedan dos iniciativas en ejecución; la calificación de proveedores de la cadena productiva de petróleo y gas, con el objetivo de fortalecer la cadena productiva, y la intensificación y complementación automotriz en el ámbito del Mercosur, para ampliar la competitividad de pequeños proveedores de autopartes. 
(En US\$ millones)

\begin{tabular}{lccc}
\hline Proyectos & Aporte del Focem & Aporte local & Total \\
\hline $\begin{array}{l}\text { I. Convergencia Estructural } \\
\text { Saneamiento urbano integrado de Aceguá/Brasil y Aceguá-ROU }\end{array}$ & 5,72 & 3,49 & $\mathbf{9 , 2 1}$ \\
II. Desarrollo y Competitividad & & & \\
Investigación, educación y biotecnologías aplicadas a la salud & 7,86 & 4,34 & $\mathbf{1 2 , 1 9}$ \\
Programa Mercosur Libre de Fiebre Aftosa (Pama) (finalizado) & 13,89 & 2,91 & $\mathbf{1 6 , 8 0}$ \\
Total & $\mathbf{2 7 , 4 6}$ & $\mathbf{1 0 , 7 5}$ & $\mathbf{3 8 , 2 1}$ \\
\hline
\end{tabular}

Fuente: Focem.

Elaboración de los autores.

La tabla 7 presenta los tres proyectos pluriestatales financiados por el Focem. Los recursos del fondo alcanzaron los US\$27,4 millones, mientras que los aportes totales ascienden a los US\$ 38,2 millones. El mayor proyecto fue finalizado: el Pama, con US\$ 13,9 millones, que incluyó a Bolivia, país asociado del bloque. Quedan dos acciones en ejecución, el saneamiento urbano integrado de Aceguá/Brasil y de Aceguá/Uruguay, en nivel bastante avanzado, e investigación, educación y biotecnologías aplicadas a la salud. ${ }^{36}$

TABLA 8

Focem: proyectos aprobados del Programa IV

(En US\$ millones)

\begin{tabular}{|c|c|c|c|}
\hline Proyectos & Aporte del Focem & Aporte local & Total \\
\hline $\begin{array}{l}\text { Identificación de necesidades de convergencia estructural en el } \\
\text { Mercosur (finalizado) }\end{array}$ & 0,07 & - & 0,07 \\
\hline Base de datos jurisprudenciales del Mercosur (finalizado) & 0,05 & - & 0,05 \\
\hline $\begin{array}{l}\text { Fortalecimiento institucional de la Secretaría del Mercosur para el } \\
\text { Sistema de Información del Arancel Externo Común (finalizado) }\end{array}$ & 0,05 & - & 0,05 \\
\hline $\begin{array}{l}\text { Fortaleciendo capacidades institucionales para la gestión de políticas } \\
\text { públicas en derechos humano en el Mercosur }\end{array}$ & 0,41 & 0,01 & 0,42 \\
\hline $\begin{array}{l}\text { Construyendo una infraestructura para la protección y promoción de los } \\
\text { derechos humanos en el Mercosur (finalizado) }\end{array}$ & 0,50 & 0,00 & 0,50 \\
\hline $\begin{array}{l}\text { Mercosur Social: fortalecimiento del Instituto Social del Mercosur y } \\
\text { consolidación del Plan Estratégico de Acción Social }\end{array}$ & 0,37 & - & 0,37 \\
\hline Total & 1,44 & 0,01 & 1,46 \\
\hline
\end{tabular}

Fuente: Focem.

Elaboración de los autores.

La tabla 8 expone las iniciativas del Programa IV, de Fortalecimiento de la Estructura Institucional y de la Integración. Los montos son pequeños en

36. Ese último proyecto existe, desde 2011, con el propósito establecer una red de institutos de investigaciones en biomedicina, que aborden de manera coordinada el tema de la salud. En abril de 2020, debido a la emergencia sanitaria generada por el Covid-19, recibió recursos adicionales de US\$15,8 millones, según datos del Mercosur de 2020. 
comparación con otros proyectos y la mayoría de las acciones son financiadas exclusivamente por el Focem. Se destacan los proyectos "construyendo una infraestructura para la protección y promoción de los derechos humanos en Mercosur", con aporte del fondo de US\$ 500 mil, y "fortaleciendo capacidades institucionales para la gestión de políticas públicas en derechos humanos en Mercosur", con US\$ 405,5 mil. Cuatro de las seis acciones ya fueron finalizadas.

Como se observa en los datos, los recursos del Focem han cumplido un rol muy relevante al proveer recursos y, al mismo tiempo, estimular contribuciones por parte de los gobiernos regionales o subregionales. Los casos de Paraguay y Uruguay, que reciben más del $92,3 \%$ del dinero del fondo, demuestran como el mecanismo contribuyó de manera decisiva para la realización de obras e iniciativas que no serían viables caso dependiesen exclusivamente de recursos de los actores locales. ${ }^{37}$

Aunque los valores aportados por cada país son aparentemente limitados, en apenas diez años, contando con el periodo inicial de tres o cuatro años de adaptación y preparación para formar equipos, empezar los análisis técnicos e iniciar la ejecución de los proyectos, la experiencia del Focem mostró que puede consolidarse como un instrumento en el combate de las asimetrías dentro de Mercosur. El fondo es un paso inicial positivo en las políticas de enfrentamiento a las desigualdades regionales. Sobre la posibilidad de aumentar los aportes, Reis (2017) plantea que

es un valor pequeño, pero hay que considerarse que son recursos no reembolsables. Entonces es muy difícil para países como Argentina y Brasil, todavía más en esa coyuntura de bajo crecimiento económico, ampliar su contribución. Quien sabe más adelante se pueda cambiar eso. Otro elemento, que también limita el aumento del monto de US\$100 millones por año es la poca mentalidad integracionista que existe en nuestros países, en especial cuando se hace ese debate en los parlamentos nacionales, donde tiene que ser tramitado ese tipo de fondo. Todavía existe mucho prejuicio, poca visión integracionista, poca visión de que el desarrollo de nuestros vecinos también es benéfico para Brasil. ${ }^{38}$

El gráfico 1, a continuación, explicita la situación actual del Focem. El primer presupuesto del fondo fue aprobado en diciembre de 2006 (Decisión CMC

37. En la interpretación de Thesing et al. (2019, p. 13, traducción nuestra), es "imprescindible el mantenimiento de las operaciones del Focem, así como la ampliación de los programas y proyectos abarcados".

38. Es razonable que exista en Brasil dificultades para legitimar el financiamiento al proceso de integración y al combate de las asimetrías. Al enfocarse en las asimetrías estructurales - territorio, población, economía y recursos naturales - existe una tendencia a atribuirle a Brasil una ventaja que no posee en otras variables. Por ejemplo, según el Banco Mundial, en 2015, el mayor país de la región posee un PIB per cápita más pequeño que el de Uruguay y el de Argentina. El IDH de Brasil igualmente es el tercero del Mercosur. Si se considera el índice de Gini, Brasil es el cuarto, atrás de Paraguay. 
no 28/2006), ${ }^{39}$ anunciando una contribución total de US\$ 125 millones (Brasil, US\$ 87,5 millones; Argentina, US\$33,75 millones; Uruguay, US\$ 2,5 millones; y Paraguay, US\$ 1,25 millón), referentes a los depósitos de US\$ 50 millones en 2006 (el 50\% de las contribuciones anuales) y US\$ 75 millones (el 75\% de las contribuciones anuales) en 2007. Por lo tanto los aportes regulares anuales de US\$ 100 millones pasaron a ocurrir desde 2008 y hasta 2013. Con el ingreso de Venezuela al Mercosur y al fondo, las contribuciones ascendieron para US\$ 127 millones en 2014 y 2015. Sin embargo, desde 2016 los países miembros dejaron de realizar sus depósitos anuales.

\section{GRÁFICO 1}

Focem: ingresos desagregados (2006-2020)

(En US\$ millones)

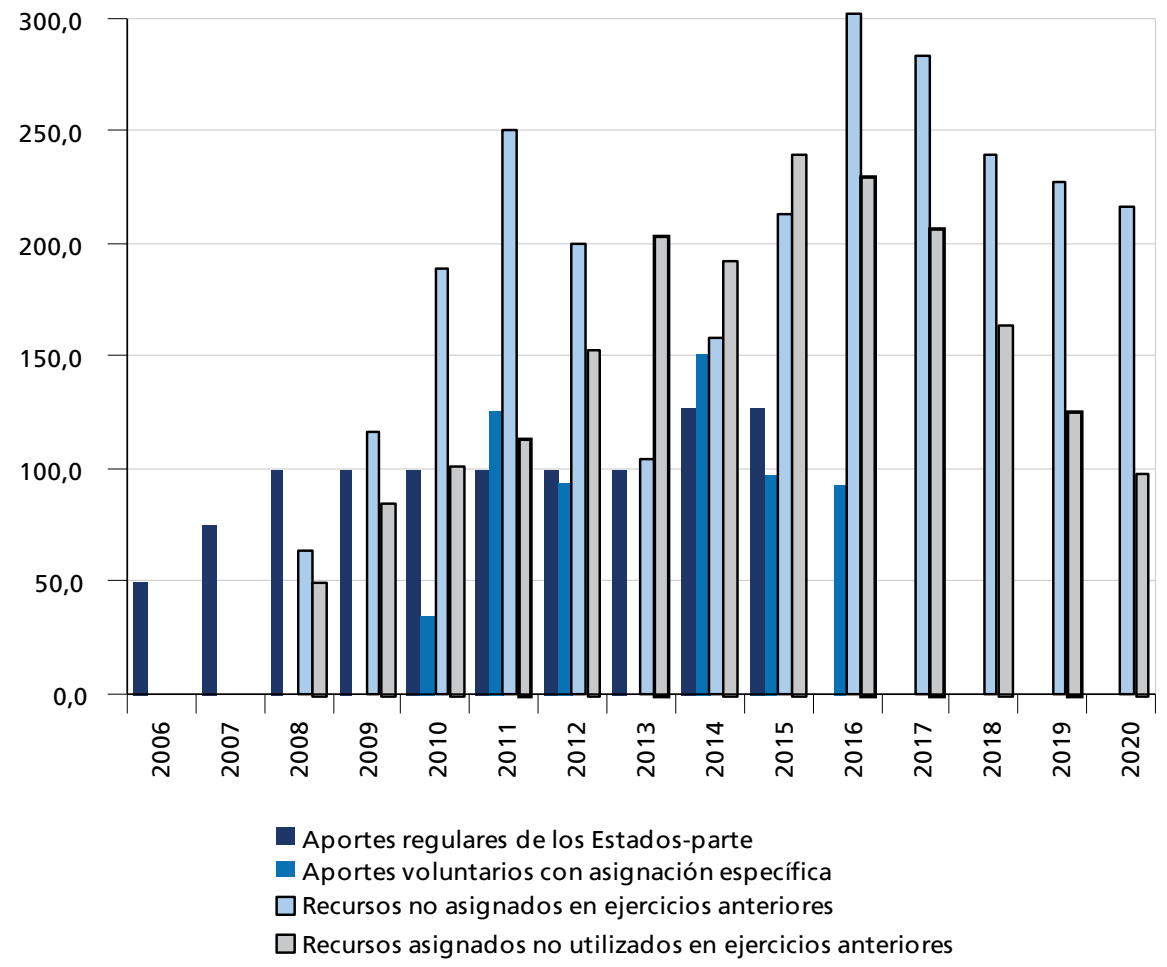

Fuente: Focem.

Elaboración de los autores. 
A su vez, los aportes voluntarios con asignación específica se hicieron de manera esporádica entre 2010 y 2016, con picos de US\$ 135,6 millones en 2011 y US\$ 151 millones en 2014. La última transferencia fue de US\$ 93,1 millones en 2016. ${ }^{40}$ Sin nuevos aportes, el Focem fue disminuyendo. Hace cinco años que los ingresos del fondo son resultado únicamente de los recursos no asignados o de los recursos asignados no utilizados en ejercicios anteriores.

El gráfico 2 expone los ingresos totales del Focem y los Montos asignados para proyectos aprobados de los Programas I, II y III. ${ }^{41}$ Se observa que hubo un momento inicial para el acumulo de recursos y la preparación de proyectos, entre 2006 y 2010. ${ }^{42}$ Esa sería la fase inicial del fondo. ${ }^{43}$ En 2011 ocurrió un salto tanto en los ingresos como en los montos asignados, correspondiente a la segunda etapa. Los aportes se mantuvieron por arriba de los US\$ 650 millones hasta 2016. Después de alcanzar un máximo de US\$ 729,4 millones en 2012 y de bajar para US\$ 706,2 millones en 2015, el total de ingresos anuales del Focem cayó por la mitad y en la actualidad está cerca de los US\$ 332,8 millones. ${ }^{44} \mathrm{Al}$ mismo tiempo, los montos asignados cayeron de manera muy evidente desde 2013: los actuales US\$ 157 millones son casi cuatro veces menores que los US\$ 580 millones de 2012. El periodo de auge del Focem, entre 2011 y 2015, demuestra la disminución en su ritmo desde 2013.

GRÁFICO 2

Focem: total de ingresos y montos asignados (2008-2020)

40. De acuerdo con los Presupuestos Anuales del Focem, todos los llamados "aportes voluntarios con asignación específica" fueron realizados por Brasil para la obra de la línea 500 kV, en Paraguay. Existen informaciones diferentes sobre esos montos en los presupuestos de 2012, 2012 actualizado y 2013. En el primer documento se informa que serían US\$ 300 millones de "Brasil aporte línea 500 kV", distribuidos en tres años, entre 2010 y 2012. El segundo corrige el monto del año 2010, mientras el tercero actualiza el valor del año 2011. Se optó por usar los datos corregidos, los últimos divulgados. La suma de "aportes voluntarios con asignación específica" hechos por Brasil alcanza los US\$641,2 millones, que representan casi los mismos US\$647,5 millones disponibilizados por ese país en forma de aportes regulares. Eso significa que el gobierno brasileño ha contribuido al Focem, en total, entre 2006 y 2016, con US\$ 1288,7 millones, equivalentes al 79,5\% de los US\$ 1620,2 millones recibidos por el fondo. A su vez, Argentina ha aportado el 15,4\% del total; Venezuela, el 3,3\%; Uruguay, el 1,1\%; y Paraguay, el 0,6\%.

41. Vale aclarar que los montos asignados no son los montos pagados. La manera que las informaciones están organizadas en la página web del Focem dificulta la identificación de los pagos anuales por país o por proyecto.

42. Los primeros proyectos fueron aprobados en 2007. Su número es decreciente a lo largo del tiempo. Durante la primera fase fueron aprobados 31; en la segunda, 10; y en la tercera, solamente seis. Se destacan los años 2007 (15 proyectos) y 2010 (10). En 2013 y 2016 no hubo proyectos aprobados. En 2017 hubo cinco y 2018, uno, el último hasta ahora.

43. Desiderá Neto y Barros (2015, p. 207-208, traducción nuestra) afirman que "aunque por motivos técnico-burocráticos haya pasado cuatro años para que su forma de funcionamiento fuese aprobada y el primer proyecto fuese ejecutado, se hizo realidad a partir de entonces en la estructura institucional del bloque un mecanismo de cooperación para el desarrollo y de enfrentamiento de las asimetrías estructurales entre los Estados-parte".

44. Ese sería el monto disponible en la cuenta para el año 2020, antes de los pagos referentes a las obras y actividades en ejecución y de la asignación para nuevas iniciativas como la investigación, educación y biotecnologías aplicadas a la salud, proyecto ampliado en abril del 2020 como parte de los esfuerzos de enfrentamiento a la pandemia. 


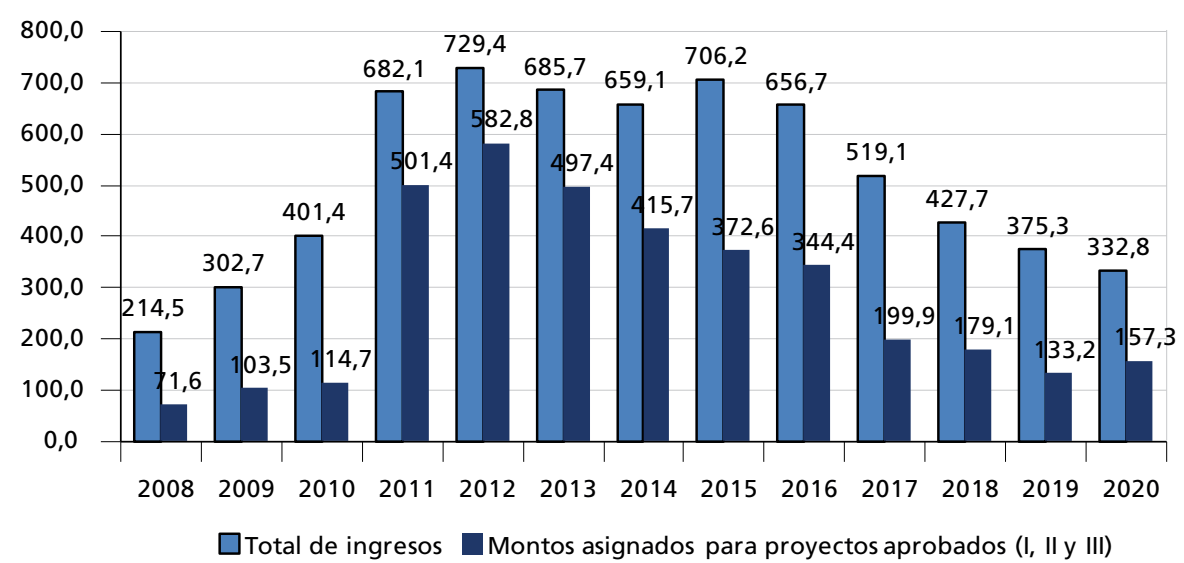

Fuente: Focem.

Elaboración de los autores.

En julio de 2015, conforme previsto, la Decisión CMC no 22/2015 estableció la renovación del funcionamiento del Focem por diez años más, para el periodo 2016-2025. Las contribuciones anuales continuaron definidas de la misma manera: Brasil, US\$ 70 millones; Argentina, US\$ 27 millones; Venezuela, US\$ 27 millones; Uruguay, US\$ 2 millones; y Paraguay, US\$ 1 millón. La distribución de los recursos destinados al financiamiento de proyectos de los Programas I, II y III sería la siguiente: Paraguay, 43,65\%; Uruguay, 29,05\%; Venezuela, 9,1\%; Argentina, 9,1\%; y Brasil, 9,1\%. ${ }^{45}$ Sin embargo, a partir de 2016 no hubo aportes al fondo.

En junio y diciembre de 2018, por medio de dos decisiones del CMC (no 2/2018 ${ }^{46}$ y no 4/2018), los Estados-parte del Mercosur y el Fonplata llegaron a un acuerdo con el objetivo de hacer un "contrato de administración fiduciaria y convenios de complementación financiera y técnica”. En el segundo documento se definieron adecuaciones en los artículos 3, 5, 6 y 15 del Reglamento del Focem (Decisión CMC no 24/2005), ${ }^{47}$ que tratan, respectivamente, de "fuentes de recursos del Focem", "institución financiera receptora de aportes", "mora en

45. Disponible en:<https://focem.mercosur.int/uploads/normativa/DEC_022-2015_PT_Renovacao\%20FOCEM-4.pdf>. 46. Disponible en: <http://www.iri.edu.ar/wp-content/uploads/2018/07/bo-alatina-64-mercosur-cmc-dec2.pdf>. 47. Disponible en: <https://focem.mercosur.int/uploads/normativa/DEC_024-2005_ES_Reglamento\%20del\%20 FOCEM-8.pdf>. 
la integración de los aportes" y "reserva de contingencia". ${ }^{48}$ Según la Decisión CMC no 4/2018,

con miras a incrementar la efectividad del Reglamento del Fondo de Convergencia Estructural del Mercosur (Focem) en la promoción de la convergencia estructural en la región, los Estados-parte se comprometen a buscar mecanismos para fortalecer la gestión institucional del Focem y la complementariedad con otros instrumentos regionales de Financiamiento al desarrollo. ${ }^{49}$

En diciembre de 2019, en la Decisión CMC no 23/2019, ${ }^{50}$ se designó al Fonplata la administración fiduciaria de los recursos financieros del Focem. En julio de 2020, durante la LVI Cumbre de Presidentes del Mercosur, los mandatarios de Argentina, Brasil, Paraguay y Uruguay aprobaron la "Norma Procesal", que reglamenta la gestión del Contrato de Administración Fiduciaria entre Mercosur y Fonplata, así como la Guía para la Administración Fiduciaria Mercosul-Focem, que permitirá la implementación del contrato. ${ }^{51}$

En su nueva etapa, fortalecido institucionalmente, el Focem puede ser potencializado e, incluso, operar como importante instrumento de financiamiento para la retomada económica post-Covid. Los quince años de aprendizaje y la actual vinculación con el Fonplata pueden facilitar la superación de limitaciones y obstáculos. En los próximos años, el Fondo para la Convergencia Estructural del Mercosur podrá asumir un rol todavía más relevante.

\section{CONSIDERACIONES FINALES}

El periodo 2003-2010 fue caracterizado por la expansión de los niveles de actividad económica en América del Sur; la ampliación de los intercambios comerciales entre Brasil y sus vecinos; y la edificación de iniciativas políticas de acercamiento, impulsadas por Brasil. Algunos de los elementos responsables de aquellos resultados fueron el fin de la unipolaridad en el Sistema Internacional, la concomitancia de coaliciones de poder reivindicadoras de una mayor presencia del Estado y la fuerte alza de los precios de las commodities. Ese conjunto de

\footnotetext{
48. Entre los principales cambios está la determinación de que cada Estado-parte debe "designar una institución financiera para depositar sus aportes, cuyas cuentas estarán a disposición del Focem". Además, se prevé que "la administración financiera de los recursos del Focem podrá celebrar acuerdos de administración financiera con otros organismos regionales de financiamiento para el desarrollo (...) exclusivamente en lo que refiere a la administración de los recursos Focem bajo administración fiduciaria del organismo regional". Disponible en: <https://focem.mercosur.int/ uploads/normativa/DEC_004-2018_PT_Adec\%20Regulamento\%20FOCEM-0.pdf>.

49. Disponible en: <https://focem.mercosur.int/uploads/normativa/DEC_004-2018_PT_Adec\%20Regulamento\%20 FOCEM-0.pdf>.

50. Disponible en:<https://focem.mercosur.int/uploads/normativa/DEC_023-2019_ES_Contrato\%20MCS-FONPLATA. docx-5.pdf>.

51. Disponible em: <https://www.mercosur.int/documento/comunicado-conjunto-dos-presidentes-dos-estados-partesdo-mercosul/s.
} 
componentes, asociados a otros, permitió que la integración regional se acelerara desde 2000, atribuyendo un peso creciente al enfrentamiento de las asimetrías.

Ese fue el contexto en el cual los países miembros del Mercosur crearon el Focem, en 2004. Desde entonces, es posible decir que el fondo tuvo tres fases distintas: la primera, entre 2006 y 2010, periodo de adaptación técnico-burocrática y de acumulo de recursos; la segunda, entre 2011 y 2015, de expansión de los financiamientos; y la tercera, post-2015, marcada por la suspensión de las contribuciones por parte de los países. En el periodo post-2015 prevaleció un cuadro de disminución en los niveles de actividad económica en América del Sur, especialmente en Brasil; reducción de la interdependencia comercial entre Brasil y sus vecinos; y de surgimiento de iniciativas políticas de fragmentación, seguidas por Brasil. Esas realidades, así como sus múltiples consecuencias, han contribuido de forma conjunta para la retracción de las iniciativas de integración regional.

Aun así, en 2015, los países del Mercosur decidieron renovar el funcionamiento del Focem por diez ańos más, para el periodo 2016-2025. Desde entonces no hubo nuevos aportes y el fondo pasó por su peor momento. En 2018 los Estados-parte del bloque y el Fonplata establecieron un acuerdo para hacer un contrato de administración fiduciaria y convenios de complementación financiera y técnica, con la manifiesta finalidad de incrementar la efectividad del Focem. En diciembre de 2019, en la reunión del Mercosur en la ciudad brasileña de Bento Goncalves, se transfirió al Fonplata la administración fiduciaria de los recursos financieros del Focem. En julio de 2020, los presidentes de los cuatro países aprobaron la Norma Procesal que reglamenta la gestión del Contrato de Administración Fiduciaria entre Mercosur y Fonplata. La vinculación del Focem con el Fonplata puede marcar el inicio de una nueva etapa, en la cual el fondo del Mercosur podrá ser potencializado.

Por fin, es importante apuntar que en marzo de 2019 se creó el Foro para el Progreso de América del Sur (Prosur), reuniendo a siete naciones: Argentina, Brasil, Chile, Colombia, Ecuador, Paraguay y Perú. En la ocasión, Bolivia, Uruguay y Surinam habían participado como observadores; después de los cambios de gobierno en La Paz y Montevideo los dos primeros países también ingresaron a la iniciativa. Entre otros puntos, la declaración final del encuentro dice:

reconocemos los aportes de procesos anteriores de integración sudamericana, así como la necesidad de preservar su acervo, en el marco de un nuevo espacio de integración más eficiente, pragmático y de estructura simple que permita afianzar sus logros y evolucionar sin duplicación de esfuerzos, hacia una región más integrada (Brasil, 2019). 
Los próximos años revelarán como avanzará el proceso de integración en América del Sur. Parece crucial que, como planteado en la reunión de fundación del Prosur, se preserve el acervo proporcionado por las experiencias anteriores. Un reciente documento publicado por el Ipea (2020, p. 55, traducción nuestra) propone "reforzar la agenda de integración regional, especialmente en materia de infraestructura, integración productiva y facilitación comercial", "acelerar la implementación de los proyectos más avanzados, como el corredor bioceánico que conectará el Centro-Oeste brasileño con los puertos del Océano Pacífico", "fortalecer el Prosur como espacio de articulación de la integración regional" y "recuperar la integración comercial y productiva con los países vecinos". Dentro de esas propuestas cabe el planteamiento de repensar la exitosa experiencia del Focem. La urgente reactivación económica post-pandemia puede requerir el impulso del fondo para promover financiamientos de conexión física, complementación comercial y articulación productiva, ahora potencializados por la estructura y la experiencia del Fonplata.

\section{REFERENCIAS}

BANDEIRA, L. A. M. O Brasil como potência regional e a importância da América do Sul na sua política exterior. Temas e Matizes, n. 14, 2008.

BARNABÉ, I. R. Do ABC ao ABV: o eixo Argentina, Brasil e Venezuela na integração da América do Sul. In: SARTI, I. et al. Por uma integraçáo ampliada da América do Sul no século XXI. Rio de Janeiro: Perse, 2013.

BRASIL. Ministerio de Relaciones Exteriores. Declaración presidencial sobre la renovación y el fortalecimiento de la integración de América del Sur Santiago, 22 de marzo de 2019. Brasília: MRE, 2019. Disponible en: <http:// www.itamaraty.gov.br/es/notas-a-la-prensa/20199-declaracion-presidencialsobre-la-renovacion-y-el-fortalecimiento-de-la-integracion-de-america-del-sur>.

BRICEÑO-RUIZ, J. Ejes y modelos en la etapa actual de la integración económica regional en América Latina. Santiago: Instituto de Estudios Internacionales, 2013. (Estudios Internacionales, n. 175). 
BUENO, C. O Brasil e o integracionismo: do $A B C$ de Rio Branco à operação pan-americana. In: FUNAG - FUNDAÇÃO ALEXNDRE GUSMÃO. A América do Sul e a integraçáo regional. Brasília: Funag, 2012.

CAETANO, G. El Mercosur en el cruce de caminos. Cuadernos del Cendes, Caracas, v. 23. n. 63, dic. 2006.

CALIXTRE, A. B.; BARROS, P. S. O Banco do Sul e o Brasil na nova arquitetura financeira regional. Brasília: Ipea, 2010. p. 19-25. (Boletim de Economia e Política Internacional).

CANO, W. Soberania e política econômica na América Latina. São Paulo: Unesp, 2000.

COUTO, L. F. Desenvolvimento, integraçáo e assimetrias: caminhos e descaminhos da aproximação regional na América do Sul. 2012. Tese (Doutorado) - Universidade de Brasília, Brasília, 2012.

CRUZ, D. A. M. de O. O Fundo para a Convergência Estrutural do Mercosul (Focem): um debate sobre as assimetrias e integração regional. São Carlos: UFSCar, 2019.

CSN - COMUNIDAD SUDAMERICANA DE NACIONES. Documento final de la Comisión Estratégica de Reflexión: un nuevo modelo de integración de América del Sur hacia la Unión Sudamericana de Naciones. Cochabamba: CSN, [2006]. Disponible en: <http://www.iirsa.org/admin_iirsa_web/Uploads/ Documents/rp_cochabamba06_csn_documento_final_comision_estrategica_ de_reflexion.pdf>.

Declaración de Margarita: construyendo la integración energética del sur. Isla de Margarita: CSN, 17 abr. 2007.

DESIDERÁ NETO, W. A. O lugar do Mercosul na Estratégia de Cooperação Sul-Sul do governo Lula (2003-2010). 2014. Dissertação (Mestrado) Universidade de Brasília, Brasília, 2014.

DESIDERÁ NETO, W. A.; BARROS, P. S. O Brasil emergente e a integração sul-americana. In: SOUZA, A. de M. e; MIRANDA, P. (Ed.). Brasil em desenvolvimento 2015: Estado, planejamento e políticas públicas. Brasília: Ipea, 2015.

FOCEM - FONDO PARA CONVERGENCIA ESTRUCTURAL DEL MERCOSUR. Focem (2005-2015). Montevideo: UTF; Secretaria del Mercosur, dic. 2015. Disponible en: <https://focem.mercosur.int/docs/FOCEM_es.pdf>. 
GARCIA, M. A. O lugar do Brasil no mundo: a política externa em um momento de transição. In: SADER, E.; GARCIA, M. A. (Org.). Brasil entre o passado e o futuro. São Paulo: Fundação Perseu Abramo; Boitempo, 2010.

GRANATO, L. A integraçáo na América do Sul em discussáo nos governos do Brasil e da Argentina (2003-2010). 2014. Tese (Doutorado) - Universidade Federal do Rio de Janeiro, Rio de Janeiro, 2014.

IPEA - INSTITUTO DE PESQUISA ECONÔMICA APLICADA. Brasil pós-Covid-19: contribuiçóes do Instituto de Pesquisa Econômica Aplicada. Brasília: Ipea, 2020.

JAGUARIBE, H. Brasil, mundo e homem na atualidade. Brasília: Funag, 2008.

MEDEIROS, C. A. de. Modelos alternativos para la integración sudamericana. $I n$ : UNCTAD - UNITED NATIONS CONFERENCE ON TRADE AND DEVELOPMENT. Integración regional en América Latina: desafíos y oportunidades - monografía de la red del Instituto Virtual de la Unctad. Nueva Iorque; Genebra: Naciones Unidas, 2010.

PADULA, R. Integraçáo regional de infraestrutura e comércio na América do Sul nos anos 2000: uma análise político-estratégica. 2010. Tese (Doutorado) Universidade Federal do Rio de Janeiro, Rio de Janeiro, 2010.

PARADISO, J. Política e integración. In: ENCUENTRO DE PENSAMIENTO POLÍTICO: PENSAR LA POLÍTICA, UN DESAFÍO EN LA TAREA DE EDUCAR, 2., 2009, La Plata, Buenos Aires. Anais... Buenos Aires: [s.n.], 2009.

PEÑA, F. La integración del espacio sudamericano: ¿̨a Unasur y el Mercosur pueden complementarse? Nueva Sociedad, n. 219, p. 46-58, ene./feb. 2009.

REIS, R. Entrevista. [Entrevista concedida a]: Mônica Karla Magalhães Lima. Montevideo, 24 oct. 2017. Audio digital (28 minutos).

RÍOS, V. Entrevista. [Entrevista concedida a]: Mônica Karla Magalhães Lima. Montevideo, 24 oct. 2017. Audio digital (23 minutos).

SEVERO, L. W. La nueva arquitectura financiera regional. Ritimo, 25 abr. 2016. Disponible en: <https://www.ritimo.org/La-nueva-arquitectura-financiera-regional>. - Integração econômica da América do Sul: liderança brasileira e desconstrução de assimetrias entre 2003 e 2014. In: ZAMBRÁO, A. et al. Economia brasileira: desenvolvimento e integração sul-americana. São Luís: Edufma, 2019. 
SOUZA, A. de M.; OLIVEIRA, I. T. M.; GONÇALVES, S. S. Integrando desiguais: assimetrias estruturais e políticas de integração no Mercosul. Rio de Janeiro: Ipea, mar. 2010. (Texto para Discussão, n. 1477).

TESSARI, G. R. Integração regional, fundos estruturais e estabilidade institucional no Mercosul: a criação do Focem. Perspectivas: Revista de Ciências Sociais, v. 42, 2012.

THESING, N. J. et al. O Mercosul e o desenvolvimento regional: contribuiçóes do Fundo de Convergência Estrutural do Mercosul - Focem. Holos, v. 7, ano 35, e5725, 2019.

UNASUR - UNIÓN DE NACIONES SUDAMERICANAS. Tratado Constitutivo de la Unión de Naciones Sudamericanas. Quito: Unasul, 2008.

\section{BIBLIOGRAFÍA COMPLEMENTARIA}

CEPAL - COMISIÓN ECONÓMICA PARA AMÉRICA LATINA Y EL CARIBE. El regionalismo abierto en América Latina y el Caribe: la integración económica al servicio de la transformación productiva con equidad. Santiago: Cepal, 1994.

CSN - COMUNIDAD SUDAMERICANA DE NACIONES. III Cumbre Sudamericana de Naciones: declaración del Cuzco sobre la Comunidad Sudamericana de Naciones. Cuzco: CSN, 8 dic. 2004.

FOCEM - FONDO PARA LA CONVERGENCIA ESTRUCTURAL DEL MERCOSUR. Informe de relevamiento de aportes, distribución y proyectos seguimiento del Focem al 31/12/2018. [s.l.]: [s.n.], 2018. Disponible en: <https:// efsur.org/wp-content/uploads/Informe-de-seguimiento-del-FOCEM-.pdf>.

GUIMARÃES, S. P. O mundo multipolar e a integração sul-americana. Temas e Matizes, n. 14, 2008.

MERCOSUR - MERCADO COMÚN DEL SUR. Decisión no 1 de 2020. Montevideo: Mercosur, 2020. Disponible en: <https://focem.mercosur.int/ uploads/normativa/Decisi\%C3\%B3n\%20CMC\%2001-20\%20PT-3.pdf>.

SAMURIO, S. E.; BARROS, P. S.; SEVERO, L. W. O protagonismo do Brasil na integração da sul-americana: uma análise das relaçóes comerciais 2000-2018.

Oikos, v. 18, n. 1, 2019. 